\title{
Preparation of a Novel Clay Loaded With Fe (VI) for Degradation of Cefazolin: Performance, Pathway and Mechanism
}

\section{Mingluo Zhou}

Southwest University of Science and Technology

\section{Riyu Zhou}

Yibin University

\section{Peng Jiang}

International Department, Chengdu Shude High School

Huili Liang

Southwest University of Science and Technology

\section{Yi Zhou}

Southwest University of Science and Technology

\section{Haiyan Chen}

Southwest University of Science and Technology

\section{Bin Wang ( $\sim$ greenworldwb@swust.edu.cn )}

Southwest University of Science and Technology https://orcid.org/0000-0002-6239-5250

\section{Shu Chen}

Southwest University of Science and Technology

\section{Weiguo Tu}

Sichuan Provincial Academy of Natural Resource Sciences and Sichuan People's Hospital

\section{Yuankun Yang}

Southwest University of Science and Technology

\section{Research Article}

Keywords: Fe (VI)-clay, cefazolin sodium, Degradation, Mechanism, DFT

Posted Date: November 2nd, 2021

DOI: https://doi.org/10.21203/rs.3.rs-985333/v1

License: (c) (1) This work is licensed under a Creative Commons Attribution 4.0 International License.

Read Full License 
Version of Record: A version of this preprint was published at Environmental Science and Pollution Research on February 15th, 2022. See the published version at https://doi.org/10.1007/s11356-02218636-x. 


\section{Abstract}

Cephalosporin antibiotics, a group of widely prescribed antibiotics, are frequently detected in wastewater effluent and in the natural aquatic environment. Materials have been sought to effectively degrade the antibiotics. In this study, a novel high-iron clay was prepared with potassium ferrate and montmorillonite via a strong alkaline in-situ synthesis method. Degradation of cefazolin sodium (CFZ) by this novel Fe (VI)-clay was investigated. The optimal conditions for the degradation of CFZ were determined using a single factor experiment and response surface optimization method. We found that $89.84 \%$ removal efficiency was obtained in $137 \mathrm{~min}$ when $\mathrm{pH}$ value was 5.16 and $\mathrm{Fe}(\mathrm{VI})$-clay dosage was $0.79 \mathrm{~g} / 100 \mathrm{~mL}$. The CFZ degradation mechanism was studied by the Density Functional Theory (DFT) in combination with spectroscopic and mass spectroscopic analysis. The spectroscopic characteristics of the products at different stages showed that the oxidation decomposition reaction occurred during the degradation of $\mathrm{CFZ}$ by $\mathrm{Fe}(\mathrm{VI})$-clay. Further, DFT calculation combined with GC-MS results showed that the degradation pathways of CFZ by the Fe ( $\mathrm{VI})$-clay was mainly the cleavage of $\beta$-lactam, thiadiazole, tetrazole and dihydrothiazine rings.

\section{Introduction}

Antibiotics play a vital role in the treatment of human infectious diseases and also in the prevention and treatment of animal diseases to improve breeding efficiency (Lu et al. 2018; Qu et al. 2019). Antibiotic residues, antibiotic-resistant bacteria (ARB), and antibiotic-resistant genes (ARGs) are considered as new water pollutants due to their potential adverse effects on aquatic ecosystems and human health (Das et al. 2019; Schwarz et al. 2021). The antibiotics widely used in healthcare, husbandry, aquaculture, etc., may accumulate in the water environment as they exist in residual amount in urine and excrement (He et al. 2020; Xu et al. 2020). In addition, even when pharmaceutical and other industrial companies comply strictly with the environmental protection regulations, the antibiotics and their intermediates in the wastewater discharged into the environment at a low concentration still accumulate (Azanu et al. 2018; Thai et al. 2018). In order to limit the spread of antibiotics in the water environment, it is necessary to develop efficient, green, and environmentally friendly antibiotic end-treatment technologies (Bajkacz et al. 2020; Zhang et al. 2020).

Cephalosporin have been widely used in the medical community because of rare anaphylactic shock, better modification and lower sensitization compared with penicillin. According to British national health statistics (McGraw et al. 2008), cephalosporin accounts for nearly one-third of antibiotics prescribed by doctors. In terms of species, there were more than 40 cephalosporin production applications worldwide. The production of cephalosporin is still increasing every year. Obviously, the environmental pollution caused by cephalosporin has also attracted great attention.

Various techniques are used to remove antibiotics including cephalosporin from the wastewater (Love et al. 2020; Bojnourd et al.2018; Qu et al. 2019; Song et al. 2019). Adsorption is an important physical and chemical method for removing antibiotics due to its simple operation, low cost and nontoxic by-product 
formation. (Lu et al. 2018). For example, the activated carbon prepared from agricultural wastes, lotus stems, wood and other raw materials showed high adsorption potential for CFZ in aqueous solution, and the removal rate was more than 80 \% (Danner et al. 2019; Zhang et al. 2018; Tian et al. 2018). Cuchitosan $/ \mathrm{Al}_{2} \mathrm{O}_{3}$ nanocomposites have been prepared, and the adsorption behavior for cefixime has been studied by Zavareh et al. (2017). In addition, Fakhri et al. studied the adsorption of CFZ and cefixime on magnesium oxide nanoparticles, and they showed that alkaline medium $(\mathrm{pH}>8)$ enhanced the absorption of cephalosporin in aqueous solution.

Clay minerals have shown potential applications to reduce antibiotics in water and wastewater due to their strong adsorption capacity, excellent mechanical and chemical stability, low cost and easy availability (Lazaratou et al. 2020; Zagursky et al. 2018). In addition to physical adsorption, chemical and electrochemical degradations of antibiotics have also been extensively investigated (Kwak et al. 2018; Duan et al. 2021; Zhao et al. 2018). The application of single-chamber microbial fuel cell in the treatment of wastewater contaminated by CFZ sodium has been reported by Zhang et al. Zhao et al. reported the degradation of 7-aminocephalosporanic acid (7-ACA) using Ag-CsPbBr 3 /CN composites under visible light irradiation. They showed that $7 \% \mathrm{Ag}-\mathrm{CsPbBr}_{3} / \mathrm{CN}$ catalyst exhibited excellent photocatalytic activity, and the degradation rate was $92.79 \%$ after 140 min. In recent years, ferrate is widely used as an oxidant additive due to its strong oxidizing activity and excellent flocculation capability. Therefore, it is critical to release it slowly into the solution and prolong the reaction time with the target pollutants, in order to maintain the high efficiency for the industrial application of ferrate (Yu et al. 2021).

Using the alkaline in-situ synthesis technology and in-situ pillaring adsorption technology, we synthesized ferrate clay with potassium ferrate and montmorillonite to improve the degradation efficiency of ferrate in water. In addition, the degradation characteristics of CFZ by high iron clay were investigated. The optimal conditions were determined by single factor experiment and response surface optimization method, and the degradation mechanism of CFZ by high iron clay was also investigated.

\section{Experimental Details}

\section{Materials}

Montmorillonite was used as the raw material to prepare high iron clay without further treatment, which was provided by Chifeng Wuhua Tianbao Mineral Resources Co. Cefazolin sodium salt, acetonitrile, and formic acid were from Sigma-Aldrich. Acetonitrile and formic acid are chromatographic grades. All the other chemicals were provided by Chron Company in Chengdu, Sichuan Province. These reagents were laboratory reagent grade and used as received without further purification. The solutions were prepared by Milli-Q purified doubly distilled water.

\section{Preparation of Fe (VI)-clay}

Firstly, an appropriate amount of montmorillonite was evenly dispersed into pure water at a content of 50 $\mathrm{g} \cdot \mathrm{L}^{-1}$. After stirred for $150 \mathrm{~min}$ at $900 \mathrm{r} \cdot \mathrm{min}^{-1}$, the mixture was allowed to stand for $24 \mathrm{~h}$. After centrifuged 
at $3000 \mathrm{r} \cdot \mathrm{min}^{-1}$ for $5 \mathrm{~min}$, supernatant and bottom residues were discarded, and the resulting montmorillonite was washed 3-5 times. Secondly, after drying at $105^{\circ} \mathrm{C}$ in the oven, the obtained solid was crushed to 200 mesh by a small crusher, and the unpulverized part was crushed to 200 mesh by a ball mill. Finally, montmorillonite was collected and stored in a dryer for use. The washed montmorillonite was referred to water-washed montmorillonite, with the name of S-Mt.

Water washed montmorillonite $100 \mathrm{~g}$ and $\mathrm{NaCl} 60 \mathrm{~g}$ were dissolved in $700 \mathrm{~mL}$ pure water. After stirred in a water bath at $70{ }^{\circ} \mathrm{C}$ for two hours, the mixture was left to stand for a moment and cool to room temperature. The mixture was centrifuged at $11000 \mathrm{r} \cdot \mathrm{min}^{-1}$ for $5 \mathrm{~min}$. The supernatant and bottom residues were discarded. The centrifuge procedure was repeated 3-5 times. Subsequently, the centrifuged clay was homogenized by using pure water to maintain an appropriate solid-liquid ratio and then dialyzed with a dialysis bag of 3500 DA. The dialysate was replaced every 4-6 hours. When the chloride detection was negative ( $0.1 \mathrm{M}$ silver nitrate solution was used for detection to show a negative Dindar effect), it was placed in an oven at $105{ }^{\circ} \mathrm{C}$ for drying and ground to 200 meshes for further use. The sodium montmorillonite was referred to sodium montmorillonite, with the name of $\mathrm{Na-Mt}$.

Na-Mt $10 \mathrm{~g}$ was mixed with $100 \mathrm{~mL}$ of an aqueous solution of $1 \mathrm{M} \mathrm{FeCl}_{3}$. The mixture was stirred at a low speed. The $1 \mathrm{M} \mathrm{FeCl}_{3}$ aqueous solution was replaced every 24 hours and continuously replaced three times. After centrifuged at $5000 \mathrm{r} \cdot \mathrm{min}^{-1}$ for $5 \mathrm{~min}$, the clay was homogenized using pure water with appropriate solid-liquid ratio dialysis at $3500 \mathrm{DA}$ and replacement of dialysate every four to six hours. When the test was negative for $\mathrm{Cl}^{-}$, the modified clay was freeze-dried and placed in a dryer after grinding. The prepared iron montmorillonite was defined as iron-based montmorillonite, with the name of Fe-Mt.

$\mathrm{Ca}(\mathrm{ClO})_{2} 40 \mathrm{~g}$ was mixed with $100 \mathrm{~mL}$ of aqueous solutions. After low-speed magnetic stirring for 30 min, it was filtered with a G3 filter funnel. The obtained filtrate was transferred to a $500 \mathrm{~mL}$ beaker. Anhydrous potassium carbonate $30 \mathrm{~g}$ was slowly added to the above filtrate under stirring. As the reaction proceeded, a large amount of $\mathrm{CaCO}_{3}$ was generated, which was stirred continuously and supplemented with a small amount of water to maintain the liquid system. Then, $200 \mathrm{~mL}$ saturated $\mathrm{KClO}$ solution was obtained by filtration using a $\mathrm{G} 3$ funnel. A solution of $45 \mathrm{~g} \mathrm{KOH}$ in $50 \mathrm{~mL}$ of ultrapure water was added to the above saturated $\mathrm{KClO}$ solution, affording a $250 \mathrm{~mL}$ alkaline saturated $\mathrm{KClO}$ solution. Subsequently, $5 \mathrm{~g}$ Fe-Mt was added slowly into the alkaline saturated $\mathrm{KClO}$ solution. After stirred in an ice water bath for 2 hours, the crude product was obtained after standing for $30 \mathrm{~min}$ and centrifugation at $5000 \mathrm{r} \cdot \mathrm{min}^{-1}$ for $5 \mathrm{~min}$. The crude product was washed with anhydrous ethanol and $\mathrm{n}$-hexane repeatedly until the residual inorganic salt ions were removed completely. The prepared oxidant named Fe (VI)-clay was stored in the dryer away from light after freeze-drying and grinding.(Tao et al. 2018)

\section{Characterization of Fe (VI)-clay}

IR spectrum was obtained using a Fourier Transform Infrared (FTIR) spectrometer to determine the structure of new Fe (VI)-clay. The analysis of the crystal structure was acquired by X-ray diffraction. 
Scanning electron microscopy (SEM) was used to observe the original surface of the large size sample directly.

\section{Degradation of CFZ by Fe (VI)-clay and the influencing factors}

The degradation of CFZ was performed using the prepared Fe (VI)-clay. $100 \mathrm{~mL}$ CFZ solution at the concentration of $100 \mathrm{mg} \cdot \mathrm{L}^{-1}$ was added into conical bottles protected with foil and stirred with a magnetic bar. The effect of reaction time was investigated at the dosage of $0.25 \mathrm{~g}, 0.50 \mathrm{~g}, 0.75 \mathrm{~g}, 1.00 \mathrm{~g}$, $1.25 \mathrm{~g}$ and $1.50 \mathrm{~g} \mathrm{Fe}(\mathrm{VI})$-clay, respectively. And the degradation efficiency was studied under $\mathrm{pH} 3,5,7,9$, and 11, respectively. The sampled solution was quenched with 2-3 drops of $0.1 \mathrm{~mol} \cdot \mathrm{L}^{-1}$ sodium thiosulfate solution and filtered through a $0.45 \mu \mathrm{m}$ filter membrane, before determination of the CFZ concentration. The experiment was carried out in three replicates.

Moreover, the response surface methodology (RSM) was used to analyze the experimental data to optimize the degradation conditions. After multiple regression fitting, the regression equation of corresponding factors could be obtained as follows:

$\mathrm{R} 1=87.24+1.54 \times \mathrm{A}-0.7562 \times \mathrm{B}+10.56 \times \mathrm{C}+2.31 \times \mathrm{AB}-1.41 \times \mathrm{AC}+0.5675 \times \mathrm{BC}-4.22 \times \mathrm{A} 2+3.78 \times \mathrm{B} 2-$ $7.10 \times \mathrm{C} 2(1)$

where, $\mathrm{R} 1, \mathrm{~A}, \mathrm{~B}$ and $\mathrm{C}$ were $\mathrm{CFZ}$ removal rate (\%), the reaction time (min), $\mathrm{pH}$, and the dosage of $\mathrm{Fe}(\mathrm{VI})$ clay $(\mathrm{g})$, respectively.

\section{Degradation mechanism of CFZ}

The degradation mechanism was investigated by analysis of products and prediction of reaction pathway. The degradation products of $\mathrm{CFZ}$ by Fe (VI)-clay under the optimal conditions were qualitatively analyzed using ultraviolet-visible spectroscopy, FTIR, excitation-emission matrix spectroscopy (EEMs) and GC-MS. The reaction intermediates and pathways were predicted based on density functional theory calculation.(Mir et al. 2020)

\section{GC-MS analysis}

The samples were pretreated with solid-phase extraction (SPE) before GC-MS analysis as follows: (1) The mixed solution was centrifuged and filtered through a $0.45 \mu \mathrm{m}$ fiber membrane, and the $\mathrm{pH}$ of filtrate was adjusted to about 3 with hydrochloric acid. (2) The SPE column was activated using $5 \mathrm{~mL}$ methanol and $5 \mathrm{~mL}$ ultrapure water before loading the sample at a rate of $5 \mathrm{~mL} \cdot \mathrm{min}^{-1}$. (3) After loading, the column was washed with $5 \mathrm{~mL}$ ultra-pure water at a rate of $2-3 \mathrm{~mL} \cdot \mathrm{min}^{-1}$, and then vacuum dried under nitrogen protection for $30 \mathrm{~min}$. (4) The SPE column was eluted with $6 \mathrm{~mL}$ methanol, and the eluent was concentrated to $1 \mathrm{~mL}$ by blowing nitrogen. The methanol solution was injected for GC-MS analysis.

\section{FED calculation and frontier orbital theory}


Computations on the Frontier Electron Density (FED), the Highest Occupied Molecular Orbital (HOMO) and the Lowest Unoccupied Molecular Orbital (LUMO) were performed by Gaussian 09 software using B3LYP6-31G $(d, p)$ basis set and continuous medium model (IEFPCM). The reaction positions were determined by $2 \mathrm{FED}^{2}{ }_{\text {HOMO }} 2 \mathrm{FED}^{2}{ }_{\text {LUMO }}$ and $\left(\mathrm{FED}^{2}{ }_{\text {HOMO }}+\mathrm{FED}^{2}{ }_{\text {LUMO }}\right)$ according to the Frontier orbital theory. The positions of electrophilic, nucleophilic, and radical reactions are identified as follows: (1) For an electrophilic reaction, the position is where the highest density of two electrons $2 \mathrm{FED}^{2}{ }_{\text {HOMO }}$ occurs when they are in the $\mathrm{HOMO}$ at ground state. (2) For a nucleophilic reaction, the position is where the highest density of two electrons 2 FED $^{2}$ LUMO occurs when they are in the LUMO at ground state. (3) For a radical reaction, the position is where the highest density of the sum of each electron

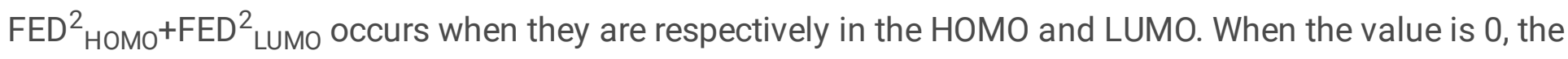
free radical reaction will take place preferentially instead of at the highest point.

\section{Results And Discussion}

\section{Characterization of the $\mathrm{Fe}(\mathrm{VI})$-clay}

As shown in Fig. 1(a), there were two characteristic absorption peaks at 3623 and $3435 \mathrm{~cm}^{-1}$ observed in natural Ca-Mg montmorillonite, which were caused by the stretching vibration absorption peak of $\mathrm{H}_{2} \mathrm{O}$ contained in the interlayer of montmorillonite and the stretching vibration peak of -OH contained in the structural water in the lattice and the interlayer adsorbed water, respectively. The absorption peak at 1638 $\mathrm{cm}^{-1}$ corresponded to Si-O-Si skeleton vibration, whereas the broad and intense peak at $1035 \mathrm{~cm}^{-1}$ corresponded to the stretching vibration peak of Si-O-Si. The characteristic peaks at $519 \mathrm{~cm}^{-1}$ and 466 $\mathrm{cm}^{-1}$ were due to the bending vibration absorption peaks of Si-O-Mg and Si-O, respectively. In Fe ( $\mathrm{VI}$ )-clay, the characteristic peak changed from a sharp peak to weak and strong absorption broadband, which may be due to the spatial steric hindrance effect that forces the bond angle between adjacent groups to change, resulting in the deviation of the vibration band and the shift of the absorption peak to about 1404 $\mathrm{cm}^{-1}$. This result further demonstrated that the $\mathrm{Fe}-\mathrm{O}$ bond in $\mathrm{Fe}(\mathrm{VI})$-clay exists between montmorillonite layers. The shoulder peak of $884 \mathrm{~cm}^{-1}$ corresponded to the characteristic peak of FeO2- 4 . In the Fe (VI)clay, the intensity of the characteristic peak decreased while the peak shifted leftward to $910 \mathrm{~cm}^{-1}$.

Figure $1(\mathrm{~b})$ showed that the $\mathrm{d}(001)$ value of natural calcium magnesium montmorillonite was $1.512 \mathrm{~nm}$, accompanied by sharp diffraction peaks, which shows that the crystallinity was very high. In the in-situ synthesized Fe $(\mathrm{VI})$-clay, the diffraction peaks of $2 \theta=28.38,40.56$, and 50.20 matched the Sylvite. syn $\mathrm{KCl}$ of PDF \# 41-14776, which indicated that the reaction in the Formula (3) occurred, and a certain amount of potassium chloride was accompanied with the in-situ synthesis of $\mathrm{K}_{2} \mathrm{FeO}_{4}$. The derivative peak of $2 \theta$ at 32.16 corresponded to the characteristic diffraction peak of $\mathrm{K}_{2} \mathrm{FeO}_{4}$ with an intensity of 123 , which may be caused by the hindrance of $\mathrm{K}_{2} \mathrm{FeO}_{4}$ in the interlaminar domain space and the decrease of crystal plane spacing. The diffraction peak of montmorillonite $d$ (001) was sharp, and the 
interlayer spacing calculated by the Bragg equation was small, indicating that $\mathrm{K}_{2} \mathrm{FeO}_{4}$ is in-situ generated in the interlayer domain.

$\mathrm{Fe}^{3+}+3 \mathrm{OH}^{-} \rightarrow \mathrm{Fe}(\mathrm{OH})_{3}(2)$

$2 \mathrm{Fe}(\mathrm{OH})_{3}+3 \mathrm{KClO}+4 \mathrm{KOH} \rightarrow 2 \mathrm{~K}_{2} \mathrm{FeO}_{4}+3 \mathrm{KCl}+5 \mathrm{H}_{2} \mathrm{O}(3)$

In Fig. 2, the morphology of montmorillonite was a stacked lamellar structure, and some lamellar structures were agglomerated into some irregular particles. Irregular tetrahedral and short rod-like crystals appeared in the pores. The particle range of these $\mathrm{K}_{2} \mathrm{FeO}_{4}$ was $0.5-3 \mu \mathrm{m}$, which was smaller than that of commercial $\mathrm{K}_{2} \mathrm{FeO}_{4}$. This may be due to the spatial limitation of the growth of $\mathrm{K}_{2} \mathrm{FeO}_{4}$ crystals generated by $\mathrm{Fe}^{3+}$ and $\mathrm{Fe}(\mathrm{OH})_{3}$ in the interlayer spacing. At the same time, the complexity of the hole structure in $\mathrm{Fe}$ (VI)-clay increased, which may be caused by the continuous growth of the crystal and occurrence of delamination, resulting in a large number of irregular concave and convex structures and significantly increased surface roughness.

\section{Degradation performance of CFZ by Fe (VI)-clay Degradation efficiency}

The time-course of CFZ concentration is shown in Fig. 3(a). As shown in Fig. 3(a), Fe (VI)-clay exhibited strong oxidizing activity in the whole reaction system. In the first $30 \mathrm{~min}$, the concentration of CFZ decreased rapidly. When the reaction time was less than $120 \mathrm{~min}$, the degradation of CFZ by Fe (VI)-clay varied significantly with time. When the reaction time was more than $120 \mathrm{~min}$, the degradation rate decreased, and various degradation products were generated, which competed with CFZ molecules. In the meantime, the color of solution gradually changed from colorless to slightly yellow, indicating that there was a certain amount of Fe (III) in the solution. The presence of Fe (III) in the solution catalyzed the selfdecomposition of $\mathrm{Fe}(\mathrm{VI})$ in $\mathrm{Fe}(\mathrm{VI})$-clay, leading to the gradual stabilization of the degradation process. When the reaction time reached $150 \mathrm{~min}$, the reaction was basically completed. In fact, CFZ was completely mineralized after $12 \mathrm{~h}$. This indicated that Fe (VI)-clay exhibited optimal slow-release degradation ability. In the subsequent experiments, we choose $150 \mathrm{~min}$ as the reaction time to ensure optimal removal effect.

The initial concentration of CFZ solution was $100 \mathrm{mg} \mathrm{L}^{-1}$, and the dosages of $\mathrm{Fe}(\mathrm{VI})$-clay was $0.25 \mathrm{~g}, 0.5$ $\mathrm{g}, 0.75 \mathrm{~g}, 1 \mathrm{~g}, 1.25 \mathrm{~g}$ and $1.5 \mathrm{~g}$, respectively. The reaction time was controlled at $150 \mathrm{~min}$. The curve of CFZ degradation rate with the dosage is shown in Fig. 3(b). As shown in Fig. 3(b), the degradation rate of $\mathrm{CFZ}$ by $\mathrm{Fe}(\mathrm{VI})$-clay varied significantly with different dosages. When the dosage was less than $0.75 \mathrm{~g}$, the removal rate of CFZ increased with the increase of Fe (VI)-clay dosage. When the dosage reached $0.75 \mathrm{~g}$, the degradation rate of CFZ reached $90 \%$. However, the degradation effect was not significantly improved by increasing the dosage. In this experiment, $0.75 \mathrm{~g}$ oxidant dosage was determined as the optimal dosage. 
Under the conditions of the initial concentration CFZ solution of $100 \mathrm{mg} \mathrm{L}^{-1}$ and the $\mathrm{Fe}(\mathrm{VI})$-clay dosage of $0.75 \mathrm{~g}$, the $\mathrm{pH}$ of the solution was adjusted to $3,5,7,9$, and 11 to investigate the effect of initial pH on the degradation of CFZ. The curve of CFZ degradation rate with $\mathrm{pH}$ is shown in Fig. 3(c). As shown in Fig. 3(c), the removal rate of CFZ was hardly affected by the $\mathrm{pH}$ of the solution. This result may be attributed to the reaction in Formula (4) of the effective component $\mathrm{K}_{2} \mathrm{FeO}_{4}$ in $\mathrm{Fe}(\mathrm{VI})$-clay, which weakens the influence of $\mathrm{pH}$.

$4 \mathrm{~K}_{2} \mathrm{FeO}_{4}+10 \mathrm{H}_{2} \mathrm{O}=4 \mathrm{Fe}(\mathrm{OH})_{3}+8 \mathrm{KOH}+6 \mathrm{O}_{2}(4)$

The oxidation ability and stability of $\mathrm{K}_{2} \mathrm{FeO}_{4}$ in $\mathrm{Fe}(\mathrm{VI})$-clay are readily affected by $\mathrm{pH}$. Under acidic conditions, the effective components in $\mathrm{Fe}(\mathrm{VI})$-clay exhibited strong redox ability but poor stability. Under alkaline conditions, the effective components in Fe (VI)-clay exhibited low redox potential and weak oxidation ability. However, CFZ is prone to self-hydrolysis in a strongly alkaline environment, increasing its degradation rate. Therefore, the $\mathrm{pH}$ effect on the degradation of $\mathrm{CFZ}$ is a combined effect on the oxidizing ability and stability of $\mathrm{K}_{2} \mathrm{FeO}_{4}$ and the stability of CFZ. In practical application, due to the deleterious effect of acidic and alkaline environment on the water treatment equipment, the optimal initial $\mathrm{pH}$ condition was determined as7.

\section{The optimal conditions}

The regression correlation coefficient of Formula (1) was 0.9483 , indicating high correlation between the predicted value and the actual value. The prediction formula can be used in the analysis of CFZ degradation and the industrial application of the $\mathrm{Fe}(\mathrm{VI})$-clay. The factors affecting the significant difference in the Formula (1) are in the order of $\mathrm{Fe}(\mathrm{VI})$-clay dosage $>$ reaction time $>\mathrm{pH}$ value. The effect of $\mathrm{Fe}(\mathrm{VI})$-clay dosage is very significant, which indicated that it directly determines the degradation efficiency of CFZ. The sum of squares was substantial, indicating that there is a specific interaction between factors. Design Expert 11 was used for response surface analysis of the data to obtain Fig. 4, and the influence of various influencing factors on the degradation effect of CFZ was analyzed.

The degradation rate of CFZ enhanced significantly with the increase of reaction time, when the reaction time was between $120 \mathrm{~min}$ and $150 \mathrm{~min}$. However, the degradation of CFZ increased slowly with the increase of time from $150 \mathrm{~min}$ to $180 \mathrm{~min}$. The sum of squares of $\mathrm{pH}$ was 4.58 , indicating that $\mathrm{pH}$ in the range of 5-9 was not a significant factor affecting the degradation of CFZ. This result is likely due to the effective component of $\mathrm{Fe}(\mathrm{VI})$-clay $\mathrm{K}_{2} \mathrm{FeO}_{4}$ in the reaction (3), weakening the effect of $\mathrm{pH}$. The dosage of $\mathrm{Fe}(\mathrm{VI})$-clay significantly affected the whole degradation system. At unit volume, the degradation rate of $\mathrm{CFZ}$ increased with the increase of $\mathrm{Fe}(\mathrm{VI})$-clay dosage. When the $\mathrm{Fe}(\mathrm{VI})$-clay dosage was increased to $0.75 \mathrm{~g}$, the degradation rate was the highest. However, when Fe (VI)-clay was continuously increased, the degradation rate of CFZ did not increase significantly.

The optimal conditions were identified via the simulation equation as following: reaction time of $137 \mathrm{~min}$, $\mathrm{pH}$ at 5.16 , and $\mathrm{Fe}(\mathrm{VI})$-clay dosage of $0.79 \mathrm{~g}$. The calculated degradation rate of CFZ was $92.28 \%$, which 
was close to the $89.84 \%$ measured under these optimal conditions. Therefore, this model is reliable to be used to optimize the operating conditions of CFZ removal.

\section{Evaluation of degradation mechanism, products and pathways}

\section{Spectral analysis of products}

Ultraviolet-visible absorption spectra of CFZ at different degradation stages are shown in Fig. 5(a). CFZ exhibited two obvious response peaks at $200 \mathrm{~nm}$ and $270 \mathrm{~nm}$. However, during the degradation process, unlike our previous study on the degradation of CFZ solution by corona discharge technology, the absorption peak intensity at $270 \mathrm{~nm}$ was not only weakened but also accompanied with a redshift. This phenomenon may be caused by the addition of $\mathrm{Fe}(\mathrm{VI})$-clay that increased the $\mathrm{pH}$ of the reaction solution. Studies have shown that CFZ in alkaline solution exhibited a redshift of $\lambda \mathrm{m}$. The decrease of absorbance indicated that the breakdown of the CFZ molecular structure, suggesting the CFZ molecule was oxidized and decomposed. Conversion of Fe (VI) to Fe (III) in Fe (VI)-clay increases the absorption at 330-450 nm.

The infrared spectra of the freeze-dried degradation solution of CFZ by Fe (VI)-clay at different times are shown in Fig. 5(b). Compared with the CFZ standard, the infrared spectra of the lyophilized degradation solution changed significantly. The characteristic peak of CFZ at $1184 \mathrm{~cm}^{-1}$ is attributed to the stretching vibration of the $\mathrm{C}-\mathrm{N}$ or acyl group. A sharp characteristic peak at $1385 \mathrm{~cm}^{-1}$ is caused by the in-plane shear swing of $-\mathrm{CH}_{3}$. The absorption peak near $1601 \mathrm{~cm}^{-1}$ corresponds to the $v_{\text {as }}\left(\mathrm{COO}^{-}\right)$asymmetric stretching vibration of $\mathrm{COONa}$. The characteristic absorption peak near $1762 \mathrm{~cm}^{-1}$ corresponds to $\mathrm{v}(\mathrm{C}=0)$ vibration of $\mathrm{C}=\mathrm{O}$ on the $\beta$-lactam ring. The characteristic peaks of $3291 \mathrm{~cm}^{-1}$ and $1667 \mathrm{~cm}^{-1}$ are caused by the stretching vibration of $-\mathrm{NH}$ in amides and $\mathrm{N}-\mathrm{H}$ in the amide I band, respectively. Peaks at 3425 $\mathrm{cm}^{-1}$ and $3291 \mathrm{~cm}^{-1}$ are the strong absorption broadband of telescopic vibrations belonging to $-\mathrm{NH}_{2}$ and $-\mathrm{NH}$, respectively. Characteristic peaks at $703 \mathrm{~cm}^{-1}, 883 \mathrm{~cm}^{-1}, 1060 \mathrm{~cm}^{-1}, 1445 \mathrm{~cm}^{-1}, 1600 \mathrm{~cm}^{-1}$, and $3235 \mathrm{~cm}^{-1}$ of freeze-dried degradant were also observed. Among them, the characteristic peak at 703 $\mathrm{cm}^{-1}$ may correspond to the $\mathrm{C}-\mathrm{H}$ out-of-plane bending vibration of terminal alkyne or the absorption band of SO2- 3.

The characteristic peaks of $883 \mathrm{~cm}^{-1}$ and $1445 \mathrm{~cm}^{-1}$ are the characteristic absorption bands of CO2-3. The characteristic peak at $1060 \mathrm{~cm}^{-1}$ may be due to the formation of degradation containing the C-O-C bonds. After degradation for $137 \mathrm{~min}$, the small absorption peak at $2093 \mathrm{~cm}^{-1}$ corresponded to the stretching vibration of triple bonds or conjugated double bonds. These IR evidence indicates that the structure of CFZ is degraded by decomposition.

Three-dimensional fluorescence spectra of CFZ at different stages of degradation are shown in Fig. 6 . The peak intensities and associated $\mathrm{Ex}_{\max }$ and $\mathrm{Em}_{\max }$ are listed in Table 1. 
Table 1

The three-dimensional fluorescence spectra of CFZ solution at different stages of degradation

\begin{tabular}{|llll|}
\hline Time(min) & Peak range/nm & Ex $_{\max } / \mathrm{Em}_{\max }$ & Fluorescence intensity \\
\hline 0 min & Ex 495-510/Em515-535 & $505 / 525$ & 19932 \\
70 min & Ex 465-480/Em515-535 & $475 / 520$ & 9875 \\
& Ex 495-510/Em515-535 & $505 / 520$ & 18569 \\
\cline { 2 - 4 } & Ex 465-480/Em515-535 & $475 / 520$ & 10736 \\
\hline \multirow{2}{*}{137 min } & Ex 490-510/Em515-535 & $500 / 520$ & 7783 \\
\cline { 2 - 4 } & Ex 465-480/Em515-535 & $515 / 475$ & 5801 \\
\cline { 2 - 4 } & & &
\end{tabular}

Figure 6 and Table 1 show that the EEMs of CFZ produced two fluorescence peaks at Ex495-510/Em515535 and Ex465-480/Em515-535. Studies have shown that the redshift of the fluorescence peak is mainly caused by the formation of functional groups such as carbonyl, hydroxyl, alkoxy, and amine. The blueshift is more likely caused by the transformation of aromatic and conjugated structures, such as the breakdown of conjugated structures, the nonlinearization of linear structures, and the replacement of carbonyl, hydroxyl, and amine groups. During the degradation process, the fluorescence intensity of fluorescence peak A decreased slowly at first and then decreased significantly. A slight blueshift and redshift occurred, which caused the splitting of the fluorescence peak into two peaks, while the fluorescence intensity at fluorescence peak B increased first and then decreased.

\section{Prediction of the reaction positions on CFZ with FED}

The FED calculation results of CFZ are shown in Fig. 7 and Table 2. According to the frontier orbital theory and the results in Table 2 and Figure 7, the locations where oxidation reactions of CFZ by Fe (VI)clay may occur can be identified. In other words, the atoms in these positions have strong reactivity, such as $1 \mathrm{C}, 2 \mathrm{C}, 6 \mathrm{C}, 7 \mathrm{C}, 19 \mathrm{C}, 22 \mathrm{C}, 3 \mathrm{~S}, 5 \mathrm{~N}, 10 \mathrm{~N}, 9 \mathrm{O}$ atoms in the parent nucleus of CFZ molecule and the $23 \mathrm{~S}$ atoms in the thiadiazole group, as well as the 11C, 140 atoms in the tetrazole group. 
Table 2

Frontier electron densities on atoms of CFZ at the B3LYP/6$31 \mathrm{G}(\mathrm{d}, \mathrm{p})$ level

\begin{tabular}{|c|c|c|c|}
\hline atom & FED $^{2}$ номо & FED $^{2}$ LUMO & FED $^{2}{ }_{\text {номо }}+$ FED $^{2}{ }_{\text {LUMO }}$ \\
\hline $1 \mathrm{C}$ & 0.20193 & 0.15879 & 0.36072 \\
\hline $2 \mathrm{C}$ & 0.03748 & 0.02787 & 0.06535 \\
\hline $3 S$ & 0.08962 & 0.02087 & 0.11049 \\
\hline $4 \mathrm{C}$ & 0.01477 & 0.013 & 0.02777 \\
\hline $5 \mathrm{~N}$ & 0.13338 & 0.03686 & 0.17024 \\
\hline $6 \mathrm{C}$ & 0.13018 & 0.14805 & 0.27823 \\
\hline $7 \mathrm{C}$ & 0.03198 & 0.11772 & 0.1497 \\
\hline $8 \mathrm{C}$ & 0.00874 & 0.0221 & 0.03084 \\
\hline 90 & 0.06584 & 0.08502 & 0.15086 \\
\hline $10 \mathrm{~N}$ & 0.00135 & 0.0096 & 0.01095 \\
\hline $11 \mathrm{C}$ & 0.00029 & 0.00175 & 0.00204 \\
\hline $12 \mathrm{C}$ & 0.00005 & 0.00104 & 0.00109 \\
\hline $13 \mathrm{~N}$ & 0.00001 & 0.00102 & 0.00103 \\
\hline 140 & 0.00052 & 0.00202 & 0.00254 \\
\hline $15 \mathrm{~N}$ & 0.00000 & 0.00125 & 0.00125 \\
\hline $16 \mathrm{~N}$ & 0.00000 & 0.00068 & 0.00068 \\
\hline $17 \mathrm{~N}$ & 0.00000 & 0.00031 & 0.00031 \\
\hline $18 \mathrm{C}$ & 0.00000 & 0.00104 & 0.00104 \\
\hline $19 \mathrm{C}$ & 0.01565 & 0.04981 & 0.06546 \\
\hline 200 & 0.01423 & 0.02656 & 0.04079 \\
\hline 210 & 0.03709 & 0.03403 & 0.07112 \\
\hline $22 \mathrm{C}$ & 0.0274 & 0.04269 & 0.07009 \\
\hline $23 \mathrm{~S}$ & 0.08132 & 0.06279 & 0.14411 \\
\hline $24 \mathrm{C}$ & 0.00978 & 0.02415 & 0.03393 \\
\hline $25 \mathrm{~N}$ & 0.01569 & 0.00953 & 0.02522 \\
\hline $26 \mathrm{~N}$ & 0.00859 & 0.00485 & 0.01344 \\
\hline
\end{tabular}




\begin{tabular}{|llll|}
\hline atom & FED $^{2}{ }_{\text {HOMO }}$ & FED $^{2}{ }_{\text {LUMO }}$ & FED $^{2}$ HOMO $^{+F_{E D}}{ }^{2}{ }_{\text {LUMO }}$ \\
\hline $27 \mathrm{C}$ & 0.00857 & 0.013 & 0.02157 \\
\hline $28 \mathrm{~S}$ & 0.00837 & 0.02302 & 0.03139 \\
\hline $29 \mathrm{C}$ & 0.00145 & 0.00251 & 0.00396 \\
\hline $30 \mathrm{H}$ & 0.0061 & 0.00788 & 0.01398 \\
\hline $31 \mathrm{H}$ & 0.02664 & 0.01047 & 0.03711 \\
\hline $32 \mathrm{H}$ & 0.00324 & 0.00516 & 0.0084 \\
\hline $33 \mathrm{H}$ & 0.00239 & 0.01029 & 0.01268 \\
\hline $34 \mathrm{H}$ & 0.00087 & 0.00373 & 0.0046 \\
\hline $36 \mathrm{H}$ & 0.00001 & 0.00009 & 0.0001 \\
\hline $37 \mathrm{H}$ & 0.00001 & 0.00021 & 0.00022 \\
\hline $38 \mathrm{H}$ & 0.00000 & 0.00014 & 0.00014 \\
\hline $39 \mathrm{H}$ & 0.00918 & 0.00504 & 0.01422 \\
\hline $40 \mathrm{H}$ & 0.00026 & 0.00059 & 0.00085 \\
\hline $41 \mathrm{H}$ & 0.0005 & 0.001 & 0.0015 \\
\hline $43 \mathrm{H}$ & 0.00071 & 0.00086 & 0.00157 \\
\hline
\end{tabular}

The intermediates of CFZ degradation were further analyzed with GC-MS, and the real-time mass spectra are shown in Fig. 8. The possible chemical structures of $\mathrm{m} / \mathrm{z}$ peaks were identified by matching with NIST14.L spectral library and DRUGBANK database combined with quantum chemistry calculation.

Studies have revealed some common degradation pathways of cephalosporins, such as thiazide ring isomerization and $\beta$-lactam ring opening. The sulfur atoms and nitrogen atoms of $\beta$-lactam in cephalosporins are usually electron-rich sites, which are vulnerable to oxidative attacks. The main ion peaks in Fig. 8 were at 101.3, 119.1, 180.0, 277.3, and $417.4 \mathrm{~m} / \mathrm{z}$. Ion peak at 101.3 was a fragment of the thiadiazole ring. The ion peak at 180 was formed by the fragmentation of the cephalosporin nucleus. We found that the ion peak at 180 was a relatively common fragment of cephalosporins. The possible molecular fragment structures of ion peaks at 277.3 and 417.4 were proposed in Fig. 8(d) and Fig. 8(e).

\section{Pathways and mechanism}


We proposed the possible degradation pathway of CFZ in Fig. 9. In pathway I, the $2 \mathrm{FED}^{2}$ HOMO of $S$ atom No.23 is 0.16264 , which indicates that it is a site for oxidative reaction. First, 5-methyl-1,3,4-thiadiazole-2methylthiol was transformed into 5-methyl-1,3,4-thiadiazole-2-thiol, and then desulphurized into 5-methyl1,3,4-thiadiazole. Subsequently, the cyclic intermediates are mineralized by ring-opening and converted into inorganic ions SO2- 3 and NO- 3. This result is consistent with the evaluation of CFZ chemical reaction sites by Fukui function and relative local softness theory. This is similar to the findings of Gurkan et al. (2012). In pathway II, the nucleus of cephalosporin contains a six-membered dihydrothiazide ring and a four-membered lactam ring. In the degradation of $\mathrm{CFZ}$ with $\mathrm{Fe}(\mathrm{VI})$-clay, the parent nucleus undergoes lactam ring decarbonylation, carboxyl carbonylation, and thiazole ring breakage, and finally mineralizes to small molecules and inorganic ions (Zhao et al. 2019). In pathway III, the tetrazole ring was cleaved at $10 \mathrm{~N}-11 \mathrm{C}$ to generate small molecule amines and finally inorganic salts, or be oxidized to $1 \mathrm{H}$-tetrazole until ring opening and mineralization to generate inorganic salts and $\mathrm{N}_{2}$, as well as other degradants.

\section{Conclusions}

$\mathrm{Fe}(\mathrm{VI})$-clay was synthesized via a strong alkaline in-situ synthesis procedure. $\mathrm{K}_{2} \mathrm{FeO}_{4}$ particles were formed in the interlayer spacing of $\mathrm{Fe}(\mathrm{VI})$-clay, ranging from 0.5 to $3 \mu \mathrm{m}$, and the growth of $\mathrm{K}_{2} \mathrm{FeO}_{4}$ particles increased the delamination. The novel Fe (VI)-clay exhibited excellent capability for the degradation of cefazolin. When the CFZ concentration was $100 \mathrm{mg} \cdot \mathrm{L}^{-1}$, the reaction was basically completed after $150 \mathrm{~min}$. The optimal conditions were identified as the reaction time of $137 \mathrm{~min}, \mathrm{Fe}(\mathrm{VI})$ clay dosage of $0.79 \mathrm{~g}$, and $\mathrm{pH}$ of 5.16. And the maximum degradation rate of CFZ was determined to be $87.96 \%$. The spectroscopic characteristics of the products at different stages showed that the oxidation decomposition reaction occurred during the degradation of $\mathrm{CFZ}$ by $\mathrm{Fe}(\mathrm{VI})$-Clay. Further, DFT calculation combined with GC-MS results showed that the main pathway of CFZ degradation by $\mathrm{Fe}(\mathrm{VI})$-clay was through the cleavage of $\beta$-lactam, thiadiazole, tetrazole and dihydrothiazide rings.

\section{Declarations}

Ethics approval and consent to participate: Not applicable

Consent for publication: Not applicable

Data availability: The datasets used and analysed during the current study are available from the corresponding author upon reasonable request.

Competing interests: The authors declare no competing interests.

Funding: This work was supported by Sichuan Science and Technology Program (Grant no. 2021YFS0284, Grant no. 2021YFS0289) and the Scientific Research Fund of Sichuan Provincial Education Department (Grant no. 18ZA0500). 
Authors' contributions: Mingluo Zhou, Riyu Zhou and Bin Wang were responsible for the conception and design of the research. Riyu Zhou, Mingluo Zhou, Huili Liang and Yi Zhou were the main experimenters of study, and were the main writers of the manuscript. Peng Jiang and Yuankun Yang contributed to the discussion and revisions. Meanwhile, Shu Chen and Weiguo Tu interpreted the results. Bin Wang and Haiyan Chen reviewed and supervised the manuscript. And all authors read and approved the final manuscript.

\section{References}

Azanu D, Styrishave B, Darko G, Weisser JJ, Abaidoo RC (2018) Occurrence and risk assessment of antibiotics in water and lettuce in Ghana. Sci Total Environ 622:293-305. https://doi.org/10.1016/j.scitotenv.2017.11.287.

Bajkacz S, Felis E, Kycia-Slocka E, Harnisz M, Korzeniewska E (2020) Development of a new SLE-SPEHPLC-MS/MS method for the determination of selected antibiotics and their transformation products in anthropogenically altered solid environmental matrices. Sci Total Environ 726. https://doi.org/10.1016/j.scitotenv.2020.138071.

Bojnourd FM, Pakizeh M (2018) Preparation and characterization of a PVA/PSf thin film composite membrane after incorporation of PSSMA into a selective layer and its application for pharmaceutical removal. Sep Purif Technol 192:5-14. https://doi.org/10.1016/j.seppur. 2017.09.054.

Danner MC, Robertson A, Behrends V, Reiss J (2019) Antibiotic pollution in surface fresh waters: Occurrence and effects. Sci Total Environ 664:793-804. https://doi.org/10.1016/j.scitotenv. 2019.01.406.

Das N, Madhavan J, Selvi A, Das D (2019) An overview of cephalosporin antibiotics as emerging contaminants: a serious environmental concern. 3 Biotech 9(6). https://doi.org/10.1007/ s13205-0191766-9.

Duan X, Zhang Y, Yan J, Zhou Y, Li G, Feng X (2021) Progress in pretreatment and analysis of cephalosporins: An update since 2005. Crit Rev Anal Chem 51(1):55-86. https:// doi.org/10.1080/10408347.2019.1676194.

Fakhri A, Adami S (2014) Adsorption and thermodynamic study of cephalosporins antibiotics from aqueous solution onto MgO nanoparticles. J Taiwan Inst Chem E 45(3):1001-

1006. https:// doi.org/10.1016/j.jtice.2013.09.028.

Gurkan YY, Turkten N, Hatipoglu A, Cinar Z (2012) Photocatalytic degradation of cefazolin over N-doped $\mathrm{TiO}_{2}$ under UV and sunlight irradiation: Prediction of the reaction paths via conceptual DFT. Chem Eng $\mathrm{J}$ 184:113-124. https://doi.org/10.1016/j.cej.2012.01.011.

He S, Sun Q, Liu Y, Li L, Yang X (2020). Acute Toxicity, Bioaccumulation, and Bioreduction of Two Antibiotics, Norfloxacin and Ofloxacin, in the Snail Bellamya aeruginosa. Water Air Soil Poll 
231(3). https://doi.org/10.1007/s11270-020-4458-5.

Kwak SJ, Yoo JC, Baek K (2018) Role of clay minerals on reduction of $\mathrm{Cr}(\mathrm{VI})$. Geoderma 312:1-

5. https://doi.org/10.1016/j.geoderma.2017.10.001.

Lazaratou CV, Vayenas DV, Papoulis D (2020) The role of clays, clay minerals and clay-based materials for nitrate removal from water systems: A review. Appl Clay Sci 185.

https://doi.org/ 10.1016/j.clay.2019.105377.

Love DC, Fry JP, Cabello F, Good CM, Lunestad BT (2020) Veterinary drug use in United States net pen Salmon aquaculture: Implications for drug use policy. Aquaculture 518.

https:// doi.org/10.1016/j.aquaculture.2019.734820.

Lu J, Wu J, Zhang C, Zhang Y, Lin Y, Luo Y (2018) Occurrence, distribution, and ecological-health risks of selected antibiotics in coastal waters along the coastline of China. Sci Total Environ 64:1469-

1476. https://doi.org/10.1016/j.scitotenv.2018.07.096.

McGraw H, Park TK (2008) Foundations in microbiology 8th edition.

Mir S, Yadollahi B, Omidyan R, Azimi G (2020) DFT study of alpha-Keggin, lacunary Keggin, and iron(II$\mathrm{VI})$ substituted Keggin polyoxometalates: the effect of oxidation state and axial ligand on geometry, electronic structures and oxygen transfer. Rsc Adv 10(56):33718-

33730. https://doi.org/10.1039/d0ra05189f.

Ou J, Li H, Ou X, Yang Z, Chen M, Liu K, Teng Y, Xing B (2020) Degradation, adsorption and leaching of phenazine-1-carboxamide in agricultural soils. Ecotox Environ Safe

205. https://doi.org/10.1016/j.ecoenv.2020.111374.

Qu J, Wang H, Wang K, Yu G, Ke B, Yu H, Ren H, Zheng X, Li J, Li W, Gao S, Gong H (2019) Municipal wastewater treatment in China: Development history and future perspectives. Front Env Sci Eng 13(6). https://doi.org/10.1007/s11783-019-1172-x.

Schwarz S, Gildemeister D, Hein A, Schroder P, Bachmann J (2021) Environmental fate and effects assessment of human pharmaceuticals: lessons learnt from regulatory data. Environ Sci Eur 33(1). https://doi.org/10.1186/s12302-021-00503-0.

Song G, Guo Y, Li G Zhao W, Yu Y (2019) Comparison for adsorption of tetracycline and cefradine using biochar derived from seaweed Sargassum sp. Desalin. Water Treat 160,316-

324. https://doi.org/10.5004/dwt.2019.24333.

Tao K, Zhao S, Gao P, Wang L, Jia H (2018) Impacts of Pantoea agglomerans strain and cation-modified clay minerals on the adsorption and biodegradation of phenanthrene. Ecotox Environ Safe 161, 237244. https://doi.org/10.1016/j.ecoenv.2018.05.091. 
Thai PK, Ky LX, Binh VN, Nhung PH, Nhan PT, Hieu NQ, Dang NTT, Tam NKB, Anh NTK (2018) Occurrence of antibiotic residues and antibiotic-resistant bacteria in effluents of pharmaceutical manufacturers and other sources around Hanoi, Vietnam. Sci Total Environ 645, 393-

400. https://doi.org/10.1016/j.scitotenv.2018.07.126.

Tian Y, Wang W, Zou W, Qian J, Hu, C (2018) Application of Solid-State NMR to reveal structural differences in cefazolin sodium pentahydrate from different manufacturing processes. Front Chem 6. https://doi.org/10.3389/fchem.2018.00113.

Xu Q, Owens G, Chen Z (2020) Adsorption and catalytic reduction of rifampicin in wastewaters using hybrid rGO@Fe/Pd nanoparticles. J Clean Prod 264. https://doi.org/ 10.1016/j.jclepro.2020.121617.

Yu H, Tian Y, Wang S, Ke X, Li R, Kang X (2021) Ferrate (VI) Oxidation Mechanism of Substituted Anilines: A Density Functional Theory Investigation. Acs Omega 6(22):14317-

14326. https://doi.org/10.1021/acsomega.1c01134.

Zagursky RJ, Pichichero ME (2018) Cross-reactivity in beta-Lactam Allergy. Aller Cl Imm-Pract 6(1):7281. https://doi.org/10.1016/j.jaip.2017.08.027.

Zavareh S, Eghbalazar T (2017) Efficient and selective removal of cefixime form aqueous solution by a modified bionanocomposite. J Environ Chem Eng 5(4):3337-

3347. https://doi.org/10.1016/ j.jece.2017.06.042.

Zhang E, Yu Q, Zhai W, Wang F, Scott K (2018) High tolerance of and removal of cefazolin sodium in single-chamber microbial fuel cells operation. Bioresource Technol 249:76-

81. https://doi.org/10.1016/j.biortech.2017.10.005.

Zhang L, Qin S, Shen L, Li S, Cui J, Liu Y (2020) Bioaccumulation, trophic transfer, and human health risk of quinolones antibiotics in the benthic food web from a macrophyte-dominated shallow lake, North China. Sci Total Environ 712:1-10. https://doi.org/10.1016/ j.scitotenv.2020.136557.

Zhao S, Ba C, Yao Y, Zheng W, Economy J, Wang P (2018) Removal of antibiotics using polyethylenimine cross-linked nanofiltration membranes: Relating membrane performa- nce to surface charge characteristics. Chem Eng J 335:101-109. https://doi.org/10.1016/j.cej. 2017.10.140.

Zhao Y, Wang Y, Liang X, Shi H, Wang C, Fan J, Hu X, Liu E (2019) Enhanced photocatalytic activity of Ag$\mathrm{CsPbBr} 3 / \mathrm{CN}$ composite for broad spectrum photocatalytic degradation of cephalosporin antibiotics 7ACA. Appl Catal B-Environ 247:57-69. https://doi.org/ 10.1016/ j.apcatb. 2019. 01.090.

\section{Figures}


Figure 1

FT-IR and XRD of montmorillonite and Fe (VI)-clay
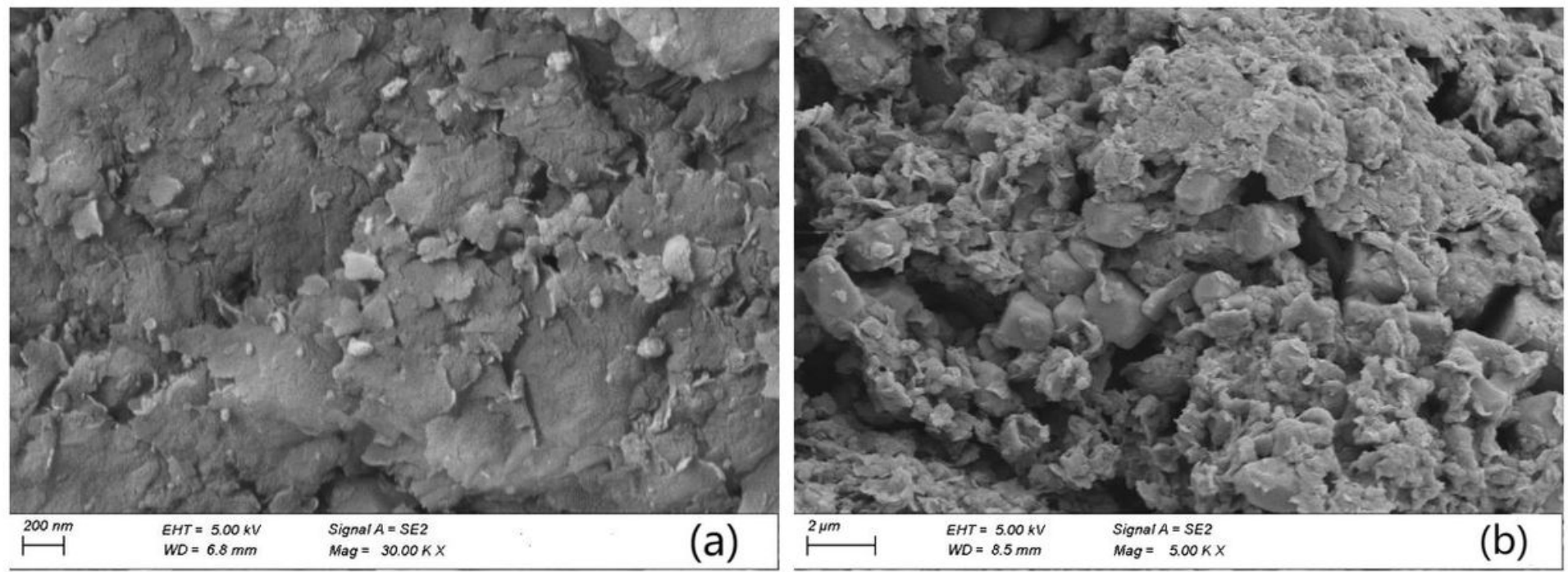

Figure 2

SEM of montmorillonite (a) and Fe (VI)-clay (b)
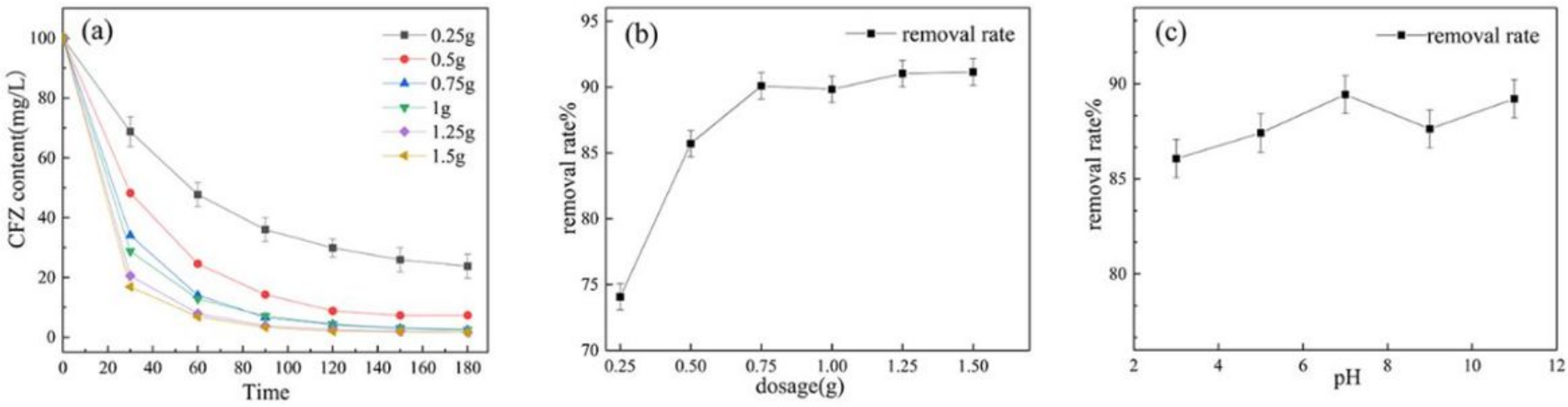

Figure 3

The effects of time (a), the dosage of Fe (VI)-clay(b) and $\mathrm{pH}(\mathrm{c})$ on $\mathrm{CFZ}$ degradation 

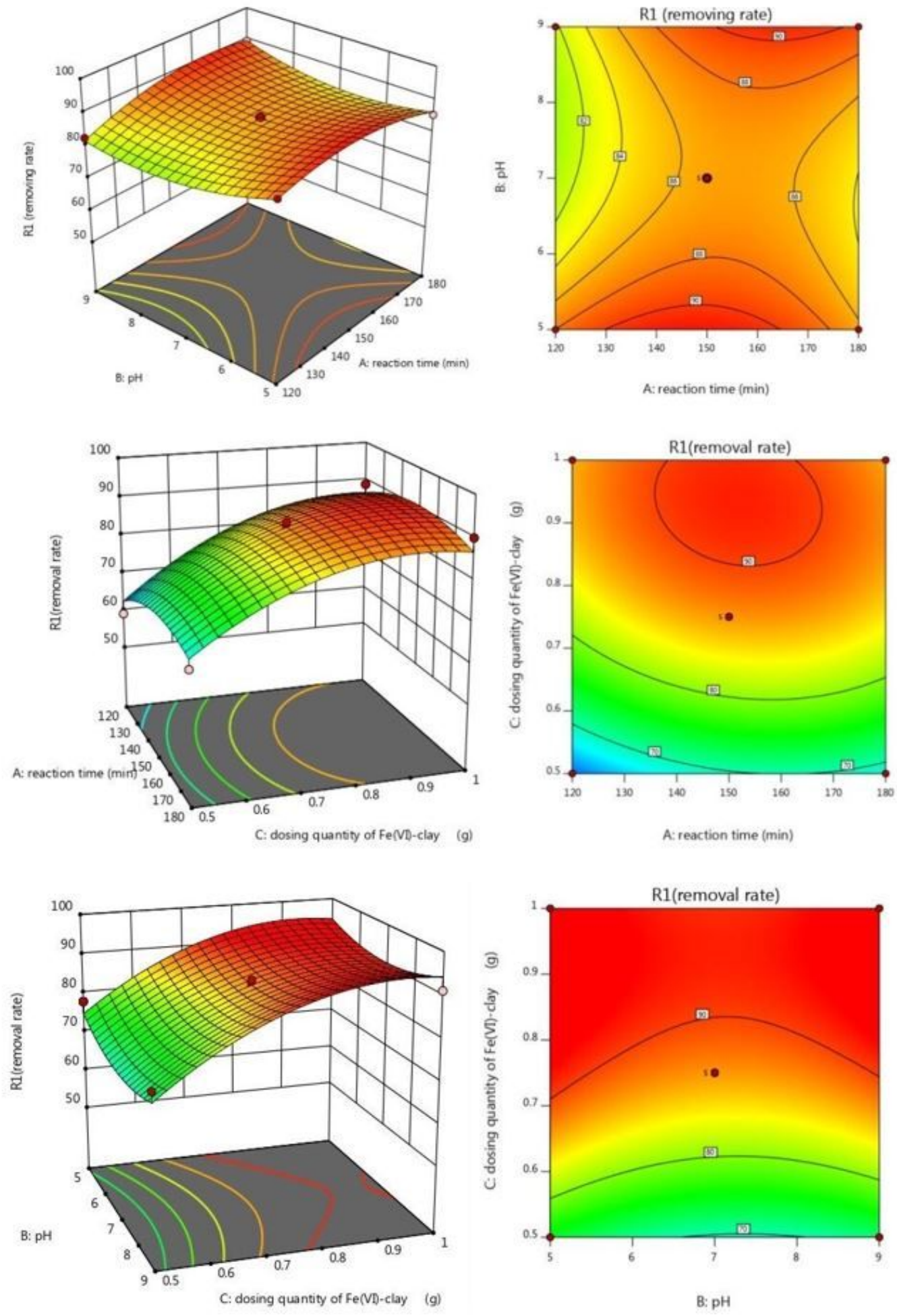

\section{Figure 4}

$\mathrm{RSM}$ and contour plot of the effect of $\mathrm{pH} \otimes \mathrm{Fe}(\mathrm{VI})$-clay dosage, and reaction time on the degradation of CFZ 

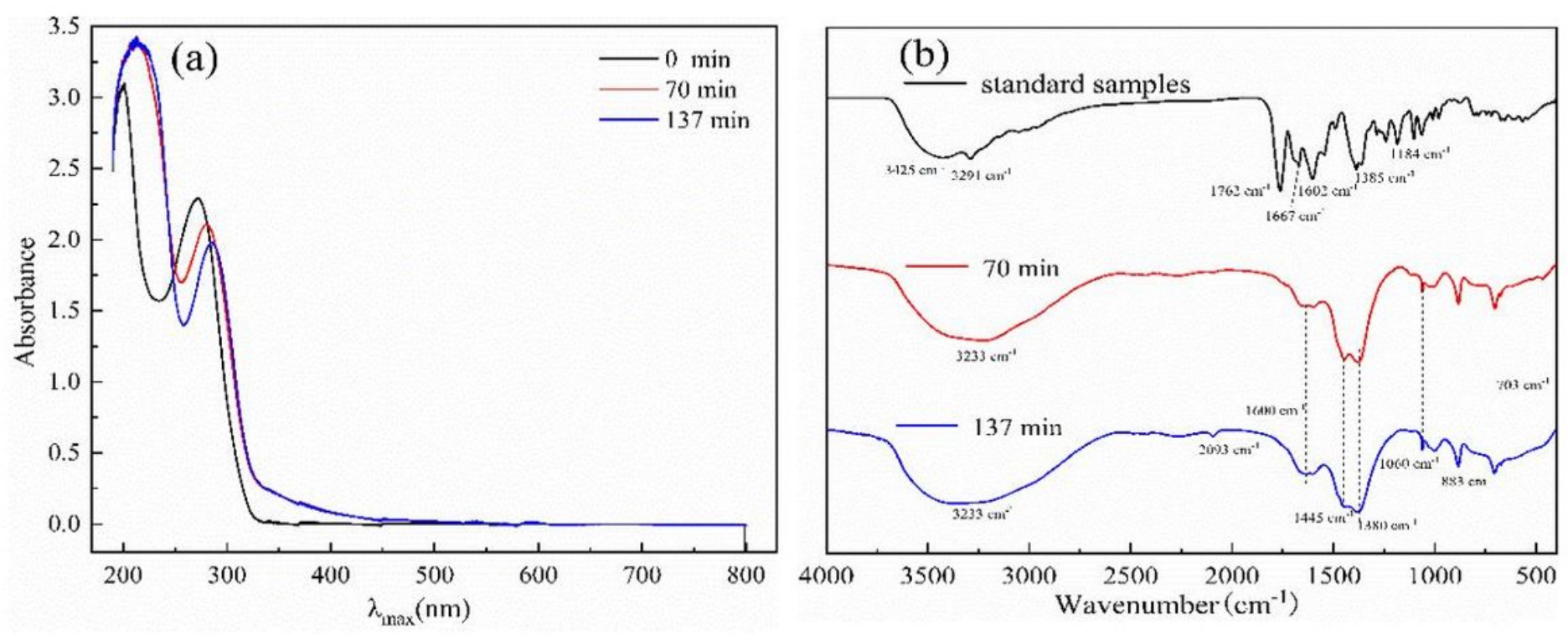

\section{Figure 5}

UV-vis absorption (a) and FT-IR spectra (b) of CFZ at different degradation stages
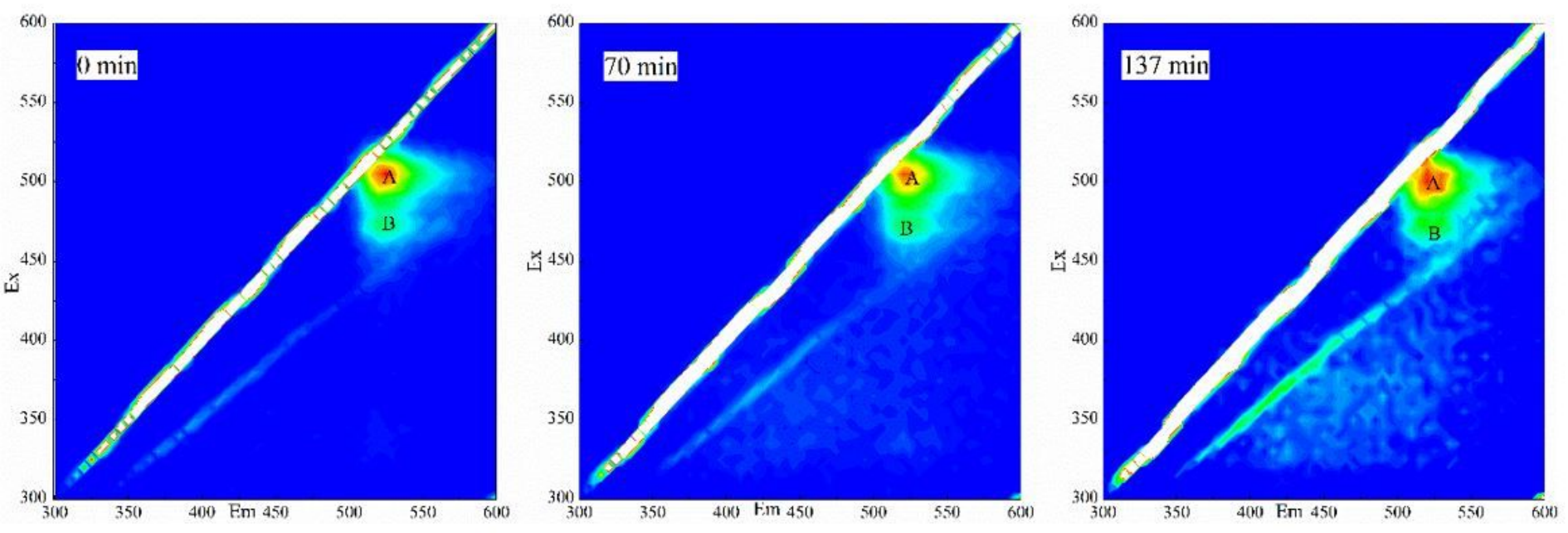

Figure 6

The EEMs of CFZ at different stages of degradation 


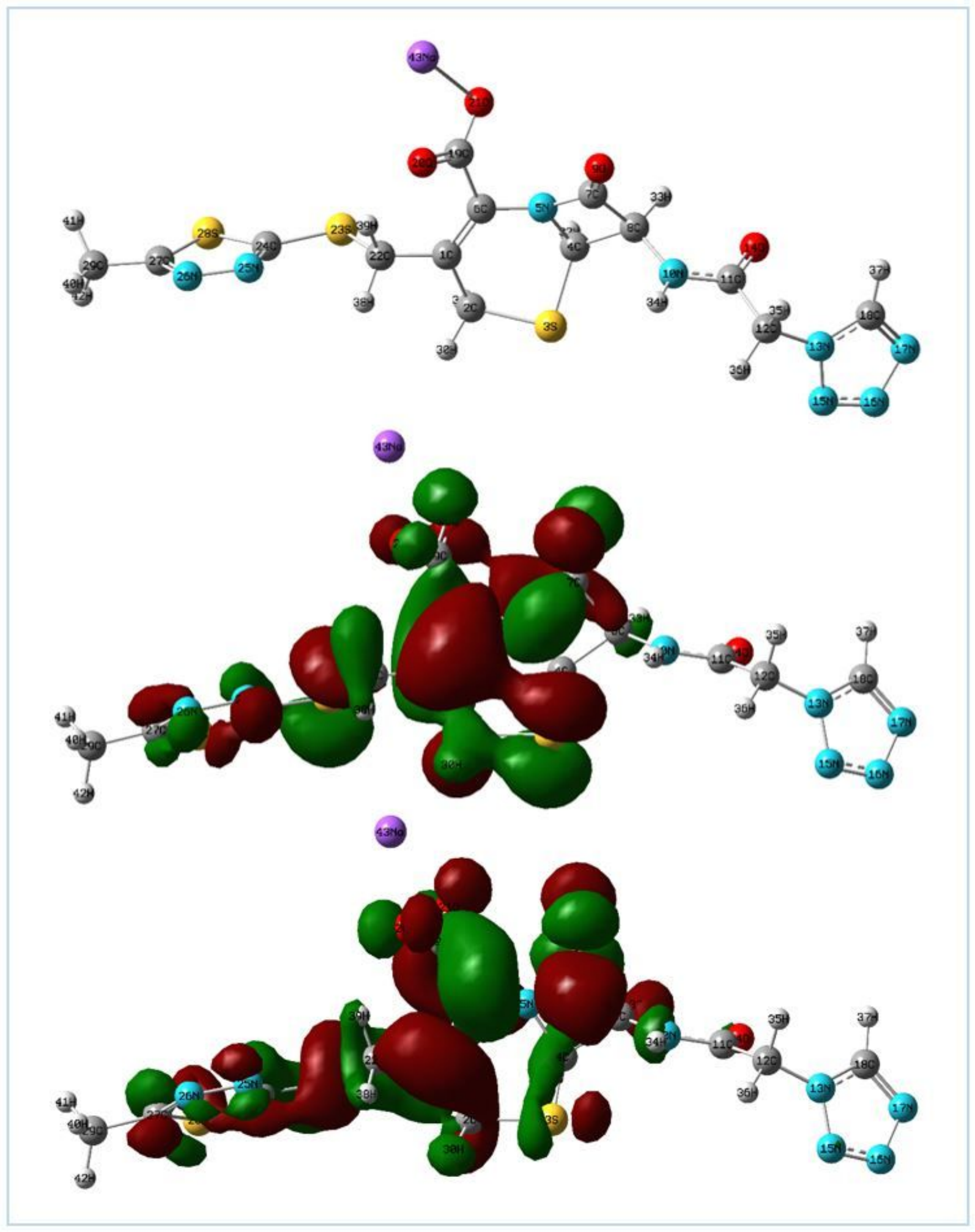

Figure 7

Atomic number diagram, $\mathrm{HOMO}$ and LUMO of CFZ 

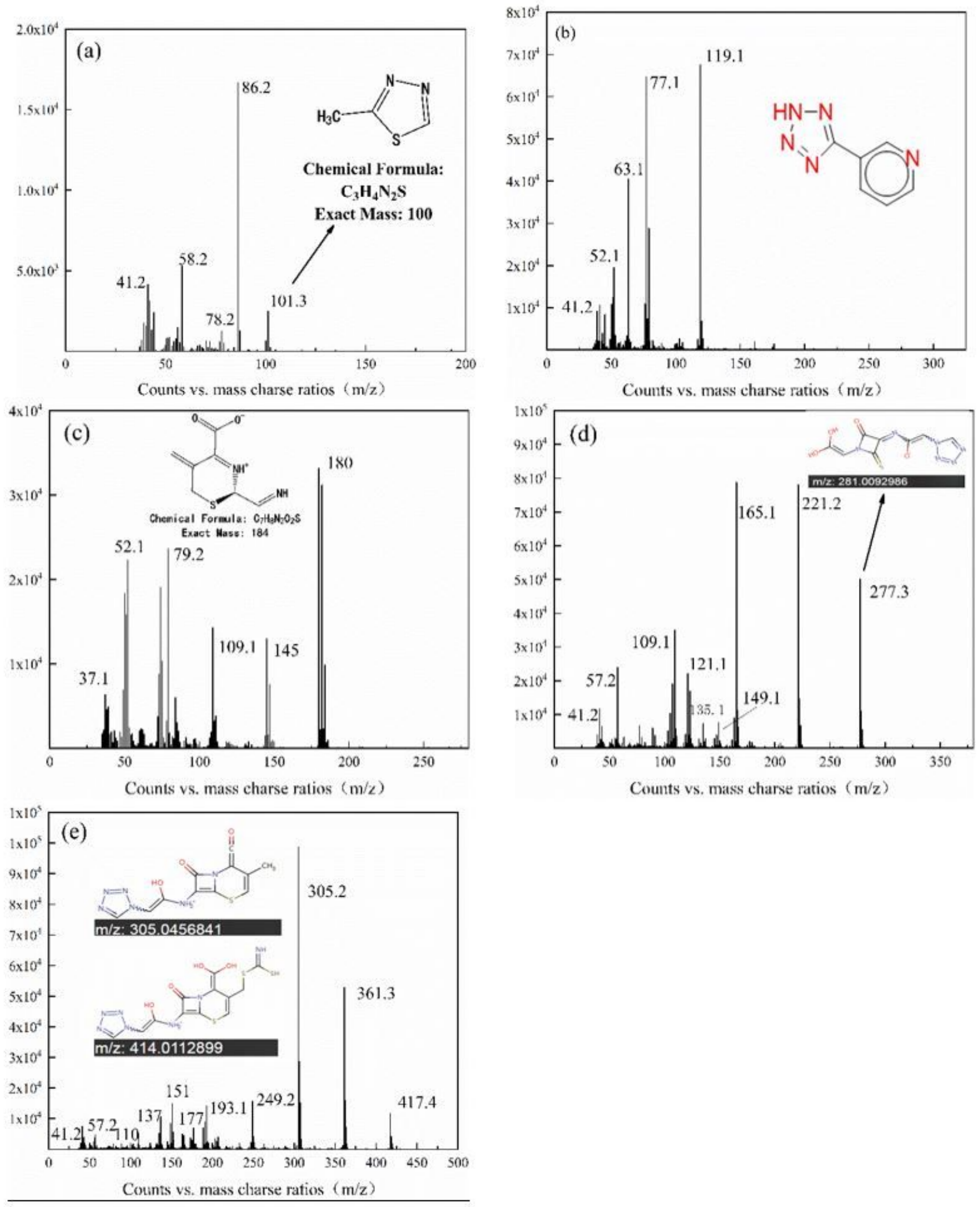

Figure 8

Real-time mass spectrometry of some degradation products of CFZ 


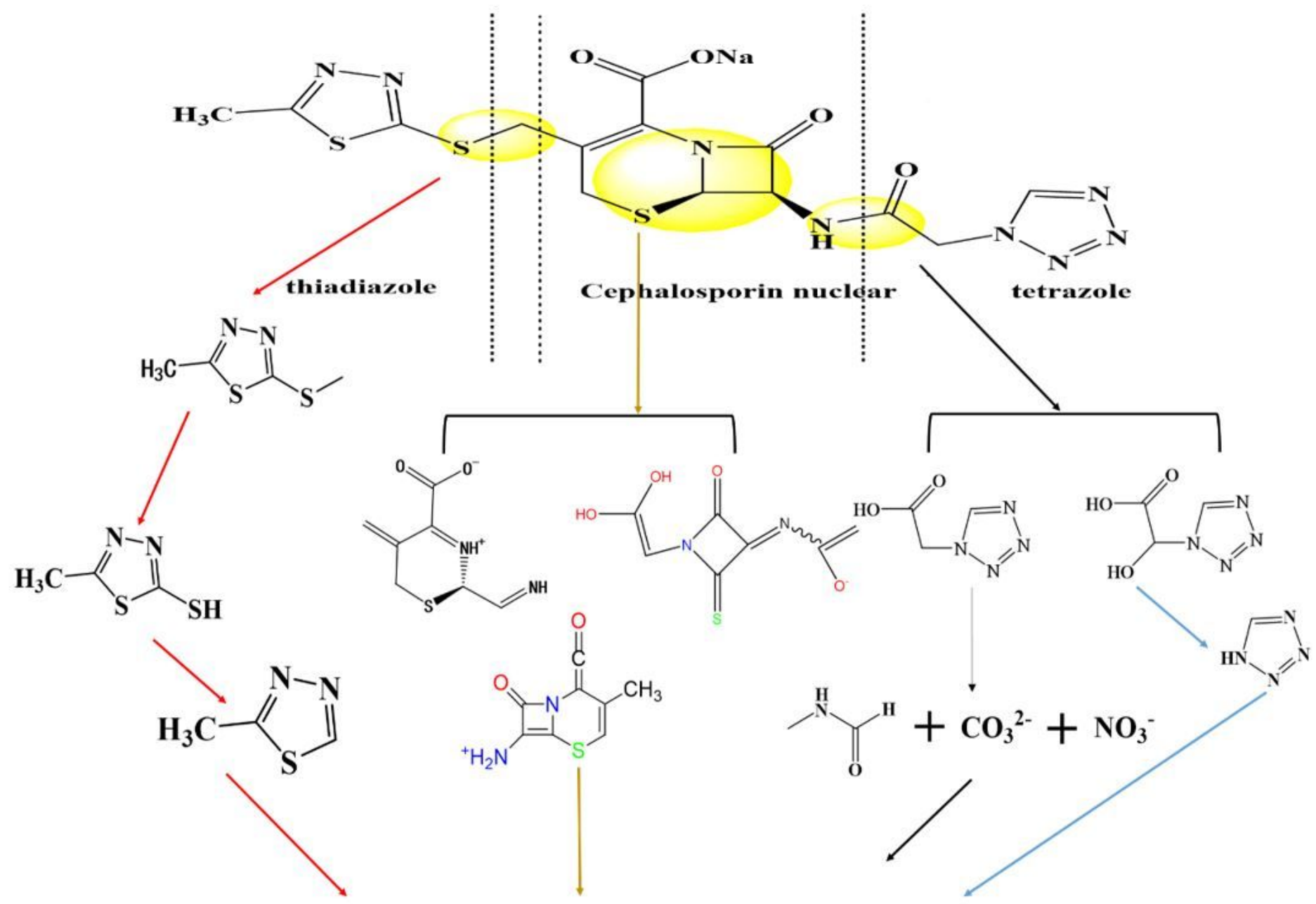

Figure 9

Possible degradation pathways of CFZ Open ring mineralization into inorganic ions, nitrogen, and other small molecules 